Orthopäde $2019 \cdot 48: 350$

https://doi.org/10.1007/s00132-019-03713-w Published online: 8 March 2019

(c) Springer Medizin Verlag $\mathrm{GmbH}$, ein Teil von Springer Nature 2019
Mohamed Ghanem · Dirk Zajonz · Rima Nuwayhid · Christoph Josten · Christoph Eckhard Heyde · Andreas Roth

Department of Orthopaedic Surgery, Traumatology and Plastic Surgery, University Hospital Leipzig, Leipzig, Germany

\section{Erratum to: Management of pelvic discontinuity in revision hip arthroplasty using a cementless acetabular cup with an iliac stem in combination with a cranial strap}

\section{Erratum to:}

Orthopäde 2018

https://doi.org/10.1007/s00132-018-

03675-5

Dear Reader,

in the original online version of the article "Management of pelvic discontinuity in revision hip arthroplasty using a cementless acetabular cup with an iliac stem in combination with a cranial strap" in the section "Material and methods" a wrong vote number of the audit authority was accidentally given.

The correct vote number of the audit authority is: 366/16-ek. The original article was updated.

We apologize for the mistake.

\section{Corresponding address}

PD. Dr. med. Mohamed Ghanem, MBA

Department of Orthopaedic Surgery,

Traumatology and Plastic Surgery, University

Hospital Leipzig

Liebigstraße 20, 04103 Leipzig, Germany

Mohamed.Ghanem@medizin.uni-leipzig.de 